\title{
MATTHEW ARNOLD ON THE TEACHING OF SCIENCE
}

BY FRED G. WALCOTT

\section{The Theory of Human Aptitudes as a Defense of Both Humane and Scientific Studies}

ARNOLD'S CHIEF CRITICISM OF THE REVISED CODE OF 1862 was inspired by his larger view of what an acceptable popular education should comprehend. Scornfully he complained that to the penny-wise proponents of the Code, "the whole duty of a State in public education is to obtain the greatest possible quantity of reading, writing, and arithmetic for the greatest number. These are, so far as the State is concerned, the education of the people."' As a humanistic educator, Arnold was distressed by the prospect of such an attenuated offering. His concept of popular education encompassed the practical and the utilitarian as well as the literary studies. Accordingly, he stood among the first men of his century to defend the liberalizing power of the new and popular science. Human aptitudes, he said, incline men to one or the other of two roads to knowledge; few are born with the genius to travel both roads:

The aim and office of instruction, say many people, is to make a man a good citizen, or a good Christian, or a gentleman; or it is to fit him to get on in the world, or it is to enable him to do his duty in that state of life to which he is called. It is none of these, and the modern spirit more and more discerns it to be none of these. These are at best secondary and indirect aims of instruction; its prime direct aim is to enable a man to know bimself and the world. Such knowledge is the only sure basis for action, and this basis it is the true aim and office of instruction to supply. To know himself, a man must know the capabilities and performances of the human spirit; and the value of the humanities, of Altertbumswissenscbaft, the science of antiquity, is, that it affords for this purpose an unsurpassed source of light and stimulus ...

... But it is also a vital and formative knowledge to know the world, the laws which govern nature, and man as a part of nature. This the realists have perceived, and the truth of this perception, too, is inexpugnable. Every man is born with aptitudes which give him access to vital and formative knowledge by one of these roads; either by the road of studying man and his works, or by the road of studying nature and her works. The business of instruction is to seize and develope these aptitudes."

When Arnold said these things, The Origin of Species had but recently been published. The year of its publication (1859) marked the first grant of funds by the State for supporting science instruction in special schools. In the same year the degree in science was instituted by the University of London. As a subject of instruction in the common schools, however, science existed, if at all, only as a trivial and rudimentary matter. Its entrance into the educational program had

FRED G. WALCOTT is a Professor of Education and English at the University of Michigan, Ann Arbor, Michigan. Previous articles by Professor Walcott appeared in the April, 1954 and the April, 1956 issues of Educational Theory.

"“The Twice-Revised Code," Fraser's Magazine, Vol. LXV, March, 1862, p. 348.

'Schools and Universities on the Continent (London, 1868), pp. 258-259. 
been by the back way. It had been accorded no part in liberal education for the simple reason that it had not been recognized as liberal. When with the rise of colleges or "institutes" for mechanics, science had found its place, the new inclusion had been completely overlooked by the Tory opponents of lower-class education, because they had failed utterly to recognize its liberal character; they saw in science only a gross, plebeian, function which they were quite willing to relegate to the "institutes." 3 Arnold's recognition of this great cultural discipline at the moment of its first impact upon traditional thought, serves as an index of his professional foresight.

According to his theory of aptitudes, Arnold recognized more than one entrance into the circle of knowledge; and the human seeker after culture would best succeed, he believed, by following his own peculiar bent. The circle was too vast, and the power of the human faculties too limited, to permit any other practical induction. Meanwhile, he thought, neither the humanists nor the realists were capable, from an extreme and isolated position, of conceiving the full circle. His proof lay in the readiness of each faction to belittle that part of the field which it could not comprehend. The humanists insisted that man's access to the realm of vital knowledge was "by knowing himself,-the poetry, philosophy, history which his spirit has created;" the realists looked rather to the sciences, to the facts and the laws of nature. ${ }^{4}$

Arnold considered neither extreme position tenable. In fact, it was only when forced to choose between the claims of one faction or the other that he would express a preference for the humanistic studies:

But it seems to me that so long as the realists persist in cutting in two the circle of knowledge, so long do they leave for practical purposes the better portion to their rivals, and in the government of human affairs their rivals will beat them. And for this reason. The study of letters is the study of the operation of human force, of human freedom and activity; the study of nature is the study of the operation of nonhuman forces, of human limitation and passivity. The contemplation of human force and activity tends naturally to heighten our own force and activity; the contemplation of human limits and passivity tends rather to check it. ${ }^{5}$

The statement is purely polemical, but it squares well with Arnold's fundamental belief. His humanism was broad and inclusive: he defended the liberalizing power of science; but if driven to choose between science and letters, he would declare an outright preference for the latter.

\section{“Literature and Science"-the Real Grounds of the Huxley-Arnold Controversy}

An understanding of Arnold's position is important in any approach to his relationship with Thomas Henry Huxley. As the champion of science, Huxley also maintained a reasonable, never an extreme, position. The inferior status of the subject, according to popular judgment, required improvement, and it was Huxley who most eminently defended its cultural values. Science had come into the educational program as an associate of the arts and crafts, and in complete 100.

${ }^{3}$ Richard Laurence Archer, Secondary Education in the Nineteenth Century (Cambridge, 1928), p.

${ }^{4}$ Schools and Universities on the Continent, p. 259.

${ }^{5}$ Ibid., p. 260. 
isolation from the respectable humanities. The Science and Art Department, organized to supervise the distribution of the South Kensington grants, ${ }^{6}$ continued as a separate institution until 1899. From 1871 to 1875 the Royal Commission on Scientific Instruction, known as the Devonshire Commission, presented a series of recommendations concerning the content of science instruction throughout the grades, and in 1872 Huxley reorganized the South Kensington "Schools of Science," and wrote the curriculum therefor. Systematic and practical as his efforts may have been, it is clear that too few teachers were available with knowledge and vision enough to bring his projects to fruition. "Nowhere," says Archer, "was the insidious system of payment by results worked out so elaborately, and nowhere was education so completely replaced by "cramming." "7 Huxley therefore serves as another of those multitudinous examples of the reformer who cannot bridge the gulf between a genuine cultural idealism and the vicissitudes of practical administration. His exposition of the cultural potentialities of practical science stands, nevertheless, as one of the great landmarks both of science and of letters. ${ }^{8}$

Arnold and Huxley, both possessed of the same idealism, surveyed the selfsame cultural problem from opposite sides-each from his own vantage point, it is true, but each in a manner resembling the other's. Between the respective views of the two men, there is a considerable basis of agreement. Even as Arnold was writing his own polemical defense of classical culture, Huxley was proclaiming substantially the same beliefs. Speaking before the South London Working Men's College in 1868, Huxley thus expressed his own concern for the classical studies:

Now, do not expect me to depreciate the earnest and enlightened pursuit of classical learning. I have not the least desire to speak ill of such occupations, nor any sympathy with those who run them down. On the contrary, if my opportunities had lain in that direction, there is no investigation into which $\mathrm{I}$ could have thrown myself with greater delight than that of antiquity.

What science can present greater attractions than philology? How can a lover of literary excellence fail to rejoice in the ancient masterpieces? And with what consistency could I, whose business lies so much in the attempt to decipher the past, and to build up intelligible forms out of the scattered fragments of long-extinct beings, fail to take a sympathetic, though an unlearned, interest in the labours of a Niebuhr, a Gibbon, or a Grote? Classical history is a great section of the palaeontology of man; and I have the same double respect for it as for other kinds of palaeontology - that is to say, a respect for the facts which it establishes as for all facts, and a still greater respect for it as a preparation for the discovery of a law of progress. ${ }^{9}$

This might well be Arnold speaking, so strong is the affinity between the educational theories of the two men. Huxley is here speaking of classical learning, of the study of the ancient languages as practiced in all the public schools and universities of the land. It was, however, a study heavily encumbered with philological formalities and endless exercises in prosody-the production by

${ }^{6}$ The grants by the State for instruction in science were called South Kensington grants, and the special schools thus supported were called South Kensington schools.

${ }^{7}$ Archer, op. cit., p. 140.

"See particularly "On the Advisableness of Improving Natural Knowledge," Methods and Results (New York, 1896), pp. 18-41. $97-98$.

9."A Liberal Education; and Where to Find It," Collected Essays (New York, 1897), Vol. III, pp. 
uncomprehending students of "lame longs and shorts." Both men knew this, and both protested vigorously against the current sterile methods; both looked yearningly beyond this dull "philological vestibule" to the higher cultural possibilities, to the great humanizing function which should be, but seldom was, realized. Huxley proceeds to voice his protest in the very next paragraph after the one quoted supra:

But if the classics were taught as they might be taught-if boys and girls were instructed in Greek and Latin, not merely as languages, but as illustrations of philological science; if a vivid picture of life on the shores of the Mediterranean two thousand years ago were imprinted on the minds of scholars; if ancient history were taught, not as a weary series of feuds and fights, but traced to its causes in such men placed under such conditions; if, lastly, the study of the classical books were followed in such a manner as to impress boys with their beauties, and with the grand simplicity of their statement of the everlasting problems of human life, instead of with their verbal and grammatical peculiarities; I still think that it is as little proper that they should form the basis of a liberal education for our contemporaries, as I should think it fitting to make that sort of palaeontology with which I am familiar the backbone of modern education. ${ }^{10}$

The basic and concluding assertion in this passage represents an important qualification, one that it is necessary to comprehend fully; its key lies in the word basis. Highly as Huxley regarded the values of classical studies, he believed that even if they were taught as they should be taught, it was still "little proper that they should form the basis of a liberal education for our contemporaries." The fund of contemporary knowledge was too vast, too significant, too immediate to the needs of modern life to be thus supplanted and eclipsed by a narrow, by an ancient culture. His quarrel, however, was only with those humanists who "take their stand upon classical education as the sole avenue to culture." $\mathrm{He}$ would by no means exclude the humanizing function of literature, even from the curriculum of the science "institutes," but he would rely upon more modern examples:

Instruction in English, French, and German is provided, and thus the three greatest literatures of the modern world are made accessible to the student.

French and German, and especially the latter language, are absolutely indispensable to those who desire full knowledge in any department of science. But even supposing that the knowledge of these languages acquired is not more than sufficient for purely scientific purposes, every Englishman has, in his native tongue, an almost perfect instrument of literary expression; and, in his own literature, models of every kind of literary excellence. If an Englishman cannot get literary culture out of his Bible, his Shakespeare, his Milton, neither, in my belief, will the profoundest study of Homer and Sophocles, Virgil and Horace, give it to him. ${ }^{11}$

It was here, within the narrow limits of this simple qualification, that the socalled controversy between Arnold and Huxley arose; and even here, within this limit, the opinions of the two men are remarkable in their essential agreement. Arnold's feeling for Huxley was one of genuine deference and admiration. Writing to his sister " $\mathrm{K}$ " in 1884, he said of the great lecturer: "He is very ill, and looks like a man quite spent. I have a real affection for him though we seldom meet; it brought the tears into my eyes to see him. But I should think he would

${ }^{10} \mathrm{Ibid}$., p. 98.

11"Science and Culture," Collected Essays (New York, 1897), Vol. III, p. 154. 
have great rallying power, when he gets real rest."12 A charming passage from the Preface to St. Paul and Protestantism reflects Arnold's eagerness to intercede for Huxley when attacked by religious zealots:

Give the churches of Nonconformity free scope, cries an ardent Congregationalist, and we will renew the wonders of the first times; we will confront this modern bugbear of physical science, show how hollow she is, and how she contradicts herself! In his mind's eye, this Nonconforming enthusiast already sees Professor Huxley in a white sheet, brought up at the Surrey Tabernacle between two deacons-whom that great physicist, in his own clear and nervous language, would no doubt describe like his disinterred Roman the other day at Westminster Abbey, as "of weak mental organization and strong muscular frame,"-and penitently confessing that Science contradicts berself. ${ }^{\text {13 }}$

There was much that was congenial between the two men: both were faithful exponents of the same true culture; both yearned steadfastly toward the same bright cynosure.

The public correspondence between the two began with Huxley's lecture before Sir Josiah Mason's College at Birmingham (1880)-that is, with his "Science and Culture" quoted supra. In this lecture he referred pleasantly to Arnold's assertion that literature contains the materials which suffice for thus making us know ourselves and the world:

Mr. Arnold tells us that the meaning of culture is "to know the best that has been thought and said in the world." It is the criticism of life contained in literature. That criticism regards "Europe as being, for intellectual and spiritual purposes, one great confederation, bound to a joint action and working to a common result; and whose members have, for their common outfit, a knowledge of Greek, Roman, and Eastern antiquity, and of one another. Special, local, and temporary advantages being put out of account, that modern nation will in the intellectual and spiritual sphere make most progress, which most thoroughly carries out this programme . .."14

Huxley saw in Arnold's statement two distinct propositions: one, that a criticism of life is the essence of culture; two, that literature furnishes the essential elements of such a criticism. To the first proposition, Huxley gave full assent; the second, he insisted, required some qualification. Literature, he believed, does lend largely to an ample criticism of life, but to rely upon this medium as the sole basis of such a criticism will produce a pattern that is incomplete. So vast, so revolutionary have been the impacts of science upon the modern world, that the facts and attitudes to be derived from this discipline must also constitute an integral part of any adequate cultural understanding, either of one's self or of the universe. "Considering progress only in the intellectual and spiritual sphere,", said Huxley, "I find myself wholly unable to admit that either nations or individuals will really advance, if their common outfit draws nothing from the stores of physical science. "I should say," he added, "that an army, without weapons of precision and with no particular base of operations, might more hopefully enter upon a campaign on the Rhine, than a man, devoid of a knowledge of what physical science has done in the last century, upon a criticism of life."1s

${ }^{12}$ Arnold Whitridge, Unpublished Letters of Matthew Arnold (New Haven, 1923), p. 54.

${ }^{13}$ Loc. cit. (New York, 1883), pp. xxxv-xxxvi. See also Culture and Anarchy (ed. cit.), p. 24, for another example of Arnold's intellectual affinity with Huxley.

${ }^{14}$ Loc - cit., pp. 142-143. Huxley is here quoting Arnold's "The Function of Criticism at the Present Time," Essays in Criticism, First Series (London, 1910), p. 39.

${ }^{15}$ "Science and Culture," ed. cit., p. 144. Arnold had himself made practically the same qualification (cp. footnote 1). 
Arnold's reply was certainly a masterpiece of restrained and temperate exposition. He protested, of course, that Huxley had fallen into the common error of limiting his (Arnold's) concept of literature to the narrow study of belles lettres. He himself had a much broader, a more sustaining theory of the humanities than this:

But when we talk of knowing Greek and Roman antiquity, for instance, which is the knowledge people have called the humanities, I for my part mean a knowledge which is something more than a superficial humanism, mainly decorative. 'I call all teaching scientific,' says Wolf, the critic of Homer, 'which is systematically laid out and followed up to its original sources. For example: a knowledge of classical antiquity is scientific when the remains of classical antiquity are correctly studied in the original languages.' There can be no doubt that Wolf is perfectly right; that all learning is scientific which is systematically laid out and followed up to its original sources, and that a genuine humanism is scientific.

When I speak of knowing Greek and Roman antiquity, therefore, as a help to knowing ourselves and the world, I mean more than a knowledge of so much vocabulary, so much grammar, so many portions of authors in the Greek and Latin languages. I mean knowing the Greeks and Romans, and their life and genius, and what they were and did in the world; what we get from them, and what is its value. That, at least, is the ideal; and when we talk of endeavouring to know Greek and Roman antiquity, as a help to knowing ourselves and the world, we mean endeavouring so to know them as to satisfy this ideal, however much we may still fall short of it. ${ }^{16}$

Like Huxley, Arnold conceived of the humanities as a great synthesis, comprehending all knowledge, including science. ${ }^{17}$ Huxley had expounded the liberalizing impact of natural science upon the spirit of man; Arnold must include science within the beneficent offices of literature; each cautions the other against circumscribing unduly the comprehensive limits of the cultural field. It was the narrow concept of humanism against which Huxley was protesting; he repudiated only "the learned specialists," who, he maintained, "possess no such sound foundation for a criticism of life as deserves the name of culture." The Renaissance, he insisted, was not wholly a revival of ancient letters, but also a revival of science. It was in their failure to comprehend this important fact that the "learned specialists" had brought reproach upon themselves; these men had failed, he said, to comprehend the "full spirit of the ancient Greek"; they had failed even in comprehending the dual aspects of the Renaissance:

In fact, the few and scattered students of nature of that day [the Renaissance] picked up the clue to her secrets exactly as it fell from the hands of the Greeks a thousand years before. The foundations of mathematics were so well laid by them, that our children learn their geometry from a book written for the schools of Alexandria two thousand years ago. Modern astronomy is the natural continuation and development of the work of Hipparchus and of Ptolemy; modern physics of that of Democritus and of Archimedes; it was long before modern biological science outgrew the knowledge bequeathed to us by Aristotle, by Theophrastus, and by Galen.

We cannot know all the best thoughts and sayings of the Greeks unless we know what they thought about natural phenomena. We cannot fully apprehend their

16"Literature and Science," Discourses in America (London, 1885), pp. 87-89. This essay was originally the Rede Lecture, given at Cambridge University, and published first in The Nineteenth Century, Vol. XII, No. 66 (August, 1882), pp. 216-230.

${ }^{17} \mathrm{Cp}$. the passage quoted supra, footnote 9, from "A Liberal Education; and Where to Find It." The difference in the two points-of-view is purely one of emphasis. 
criticism of life unless we understand the extent to which that criticism was affected by scientific conceptions. We falsely pretend to be the inheritors of their culture, unless we are penetrated, as the best minds among them were, with an unhesitating faith that the free employment of reason, in accordance with scientific method, is the sole method of reaching truth. ${ }^{18}$

Huxley was demonstrating, in fact, that even the modern scientist must build upon the old foundation as recorded in the classical authors. He insisted only that the "criticism of life" to be obtained from those authors must be incomplete so long as it failed to comprehend what had been a considerable portion of their knowledge - that is, the scientific concepts which they had held. Arnold was quick to follow this extraordinary lead. Said Arnold:

But as I do not mean, by knowing ancient Rome, knowing merely more or less of Latin belles lettres, and taking no account of Rome's military, and political, and legal, and administrative work in the world; and as, by knowing ancient Greece, I understand knowing her as the giver of Greek art, and the guide to a free and right use of reason and to scientific method, and the founder of our mathematics and physics and astronomy and biology,-I understand knowing her as all this, and not merely knowing certain Greek poems, and histories, and treatises, and speeches, - so as to the knowledge of modern nations also. By knowing modern nations, I mean not merely knowing their belles lettres, but knowing also what has been done by such men as Copernicus, Galileo, Newton, Darwin. ${ }^{19}$

Arnold has taken his words from Huxley's own mouth and rendered his own thought back to him. Huxley had protested against a narrow concept of humanism, one that excluded science; Arnold merely emphasized his own agreement. If Huxley had misapprehended Arnold's ideas of culture and ascribed to him a narrow instead of a broad concept, he (Arnold) had only to correct that misapprehension to bring the two into harmony. And so without repudiating his opponent in any mean way, Arnold thus maintains an equitable defense:

Let us therefore, all of us, avoid indeed as much as possible any invidious comparison between the merits of humane letters, as means of education, and the merits of the natural sciences. But when some President of a Section for Mechanical Science insists on making the comparison, and tells us that "he who in his training has substituted literature and history for natural science has chosen the less useful alternative,' let us make answer to him that the student of humane letters only, will, at least, know also the great general conceptions brought in by modern physical science; for science, as Professor Huxley says, forces them upon us all. But the student of the natural sciences only, will, by our very hypothesis, know nothing of humane letters; not to mention that in setting himself to be perpetually accumulating natural knowledge, he sets himself to do what only specialists have in general the gift for doing genially. And so he will probably be unsatisfied, or at any rate incomplete, and even more incomplete than the student of humane letters only. ${ }^{20}$

The controversy thus concluded exemplifies the intellectual affinity between the two men; but more important still, it reveals the intellectual modernity that characterized the two great thinkers, a breadth of cultural vision that renders their kindred judgments valid and contemporary.

18"Science and Culture," loc. cit., Vol. III, pp. 151-152.

19"Literature and Science," loc. cit., pp. 91-92.

${ }^{20}$ Ibid., pp. 125-126. 


\section{Arnold as an Exponent of the Scientific Method}

The impregnation of the humanist's mind with "the great general conceptions brought in by modern physical science" was an actuality with Arnold himself. Not only did he reveal his familiarity with the great figures of science and their general theses, but he displayed at least an amateur's respect for research and the scientific method. It is true that his own use of scientific methods may have sometimes fallen short, for he employed them usually in polemical matters, such as theories of religious faith, where experiment is impracticable. He speculated scientifically, a different thing from using scientific methods. An example may be found in his On the Study of Celtic Literature (1867). Here he became engrossed by the work of the modern ethnologists in their study of the natural relationships between racial groups: "the doctrine of a great Indo-European unity, comprising Hindoos, Persians, Greeks, Latins, Celts, Teutons, Slavonians, on the one hand, and, on the other hand, of a Semitic unity and of a Mongolian unity, separated by profound distinguishing marks from the Indo-European unity and from one another,..."'21 He speculated with some zest on the harmonic affinities which members of the same unity might naturally detect in one another, despite long geographic and cultural isolation. In this new scientific whimsy, he thought he saw a means, perhaps, of gratifying the wishful dream of many an Englishman, a hope and a justification for assimilating the incorrigible Celt through the discovery of a common strain of temperament, a potential compatibility as yet unrecognized, instead of a genuine ethnic antipathy. And all this was to be had through the simple ministration of scientific research.

This tendency [to recognize racial affinities] is now quite visible even among ourselves, and even, as I have said, within the great sphere of the Semitic genius, the sphere of religion; and for its justification this tendency appeals to science, the science of origins; it appeals to this science as teaching us which way our natural affinities and repulsions lie. It appeals to this science, and in part it comes from it; it is, in considerable part, an indirect practical result from it. ${ }^{22}$

If such speculation appears somewhat tenuous, Arnold had at least learned from the scientists a very serviceable device, a clear setting of one's inferential limits and a careful guarding of one's retreat. Hence it is not surprising to hear him say later,

However, it is not my intention, in these remarks, to lay it down for certain that this or that part of our powers, shortcomings, and behaviour, is due to a Celtic, German, or Norman element in us. To establish this I should need much wider limits, and a knowledge, too, far beyond what I possess; all I purpose is to point out certain correspondences, not yet, perhaps, sufficiently observed and attended to, which seem to lead towards certain conclusions. The following up the inquiry till full proof is reached,--or perhaps, full disproof,-is what I want to suggest to more competent persons. ${ }^{23}$

The important point is that Arnold exemplified his own claim: he, a humanist, had encountered the ethnological and philological ideas of his time and had absorbed them with zest and delectation. He had, furthermore, some sense of the scientific method, enough at least to prompt him to caution in his own statements.

${ }^{21}$ Idem. (New York, 1883), p. 15.

2 Ibid., pp. 16-17.

${ }^{23}$ Ibid., p. 91. 
Even in religious matters, Arnold sought to maintain and to apply a scientific method. The professional scientist may smile at the thought, but there are many who will recognize something substantial and impressive in Arnold's systematic thinking. Remembering the vituperations hurled at science by the zealots even of the present day, they will find refreshment in Arnold's forthright manner:

And first let us premise what we mean in this matter by primary and secondary, essential and subordinate. We mean, so far as the apostle is concerned, a greater or less approach to what really characterises him and gives his teaching its originality and power. We mean, so far as truth is concerned, a greater or less agreement with facts which can be verified, and a greater or less power of explaning them. What essentially characterises a religious teacher, and gives him his permanent worth and vitality, is, after all, just the scientific value of his teaching, its correspondence with important facts, and the light it throws on them. Never was the truth of this so evident as now. The scientific sense in man never asserted its claim so strongly; the propensity of religion to neglect those claims, and the peril and loss to it from neglecting them, never were so manifest. The license of affirmation about God and his proceedings, in which the religious world indulge, is more and more met by the demand for verification ... It is true, when the scientific sense in us, the sense which seeks exact knowledge, calls for that verification, Calvinism refers us to St. Paul, from whom it professes to have got this history of what it calls "the covenant of redemption." But this is only pushing the difficulty a stage further back. For if it is St. Paul, and not Calvinism, that professes this exact acquaintance with God and his doings, the scientific sense calls upon St. Paul to produce the facts by which he verifies what he says; and if he cannot produce them, then it treats both St. Paul's assertion, and Calvinism's assertion after him, as of no real consequence. ${ }^{24}$

It would be irrelevant to trace further Arnold's handling of the St. Paul thesis, and to examine whether or not he (Arnold) meets the test of scientific method. The important point is that here was a writer of the 19 th Century cogently considering the methods of science and deliberately proposing to apply them as a test of the soundness of religious doctrine, doing this at the moment when the votaries of formalized religion were venting their maledictions upon the new agnostics who would set facts and the observations of nature above the authority of established creeds. ${ }^{25}$ Arnold was by nature a devout and reverent man. The fact that he could accommodate the most advanced ideas of his day, even become their fearless advocate, clearly marks his imposing intellectual stature and places him as completely abreast of the prophetic tendencies of his time.

\section{Arnold's Ideas on Science as a Curricular Inclusion}

But with Arnold the educator, we should expect to gauge the importance he would attach to science largely by the place he would accord to it in the curriculum. Perspective is all-important in examining his comments; it must never be forgotten that in dealing with science he is concerned with what stands in the popular mind as an innovation, with what would today be placed by a large portion of the critical public in the category of "fads and frills."

${ }^{24}$ St. Paul and Protestantism (New York, 1883), pp. 6-7.

${ }^{25}$ The importance which Arnold attributed to his religio-scientific theme may be gauged by the long interval of his preoccupation with it. For eight years he devoted himself assiduously to the exposition of it, an effort that resulted in the publication of four major works: St. Paul and Protestantism (1870), Literature and Dogma (1873), God and the Bible (1875), and Last Essays on Church and Religion (1877). 
Notwithstanding the high place that Arnold would accord to literature and the humanities-themselves "fads and frills" in the elementary and secondary schools of his day-he would, nevertheless, reserve an honored place for science. In fact, in his comparison of the British secondary schools with those of the Continent, it was the inferior development of the instruction in science that most characterized the disadvantages of the former; and when comparing instruction in science with that of the humanities in the British schools, it was the ineffectuality of the teaching of science that most accentuated the inferior status of this subject in the popular mind:

. . . we may willingly declare with the Italians that no part of the circle of knowledge is common or unclean, none is to be cried up at the expense of another. To say that the fruit of classics, in the boys who study them, is at present greater than the fruit of the natural sciences, to say that the realists have not got their matters of instruction so well adapted to teaching purposes as the humanists have got theirs, comes really to no more than this: that the realists are but newly admitted labourers in the field of practical instruction, and that while the leading humanists, the Wolfs and the Buttmanns, have been also schoolmasters, and have brought their mind and energy to bear upon the school-teaching of their own studies, the leaders in the natural sciences, the Davys and the Faradays, have not. When scientific physics have as recognised a place in public instruction as Latin and Greek, they will be as well taught. ${ }^{26}$

It is for the rising middle class that science, according to Arnold's judgment, stands as the great paramount need. This great middle class, thwarted and deprived of its social rights through the indifference of the superior classes and its own ignorant complicity, brought up on the second plane, insufferably and arrogantly proud of its own inanities-if only it might have science as a compensating benefit:

If only, in compensation, it had science, systematic knowledge! The stronghold of science should naturally be in a nation's middle class, who have neither luxury nor bodily toil to bar them from it. But here comes in the intellectual inconvenience of the bad condition of the mass of our secondary schools ... Short as the offspring of our public schools and universities come of the idea of science and systematic knowledge, the offspring of our middle class academies probably come, if that be possible, even shorter. What these academies fail to give in social and governing qualities, they do not make up for in intellectual power. ${ }^{27}$

In thus prescribing for the needs of the middle class, Arnold meant to advocate no educational stratification; he implied no acceptance of the common illusory judgment of his time concerning the inferior place of science in the scale of intellectual respectability. It is undoubtedly true that he spoke from an awareness of its utilitarian, as well as of its cultural, values. The facts are, however, that despite any reservations that he might have had in comparing science with Alterthumswissenschaft as a cultural agent, he was still a strong advocate of science as an addition to the secondary curriculum of his time--and this because of his own temperamental inclinations.

Arnold's active interest in science extended also to his recommendations for the elementary schools. In his Report to the Committee of Council for the year 1876 , he again discussed the relative importance of literature and science as branches of the elementary curriculum. Here, however, his solicitude for the humanities

${ }^{26}$ Schools and Universities on the Continent, pp. 260-261.

${ }^{27}$ Ibid., p. 277. 
had been newly quickened by the recent exertions of the special advocates of science; in fact, one will recognize in this report one of the sources of Arnold's reply to Huxley's lecture before Sir Josiah Mason's College. ${ }^{28}$ In his perturbation he pleaded here for the humanizing, moralizing functions of literature, as the catalyzing agent whereby the utilitarian values of science might be realized:

To have the power of using, which is the thing wished, these data of natural science, a man must, in general, have first been in some measure moralised; and for moralising him it will be found not easy, I think, to dispense with those old agents, letters, poetry, religion. So let not our teachers be led to imagine, whatever they may hear and see of the call for natural science, that their literary cultivation is unimportant. The fruitful use of natural science itself depends, in a very great degree, on having effected in the whole man, by means of letters, a rise in what the political economists call the standard of life. ${ }^{29}$

One must not be misled by this earlier predisposition to acclaim the humanities; it reflects no dilatory indecision. Even here Arnold implied no disparagement of the sciences. In his next Report, for the year 1878, he became much more constructive, more specific, in his comments upon the science that was being offered in the elementary schools:

In my last report ${ }^{30}$ I proposed that what the Germans call Natur-kunde-some knowledge of the facts and laws of nature-should be taught as a class-subject ${ }^{31}$ in addition to grammar, geography, and English history. This has been treated as a proposal to amplify our present programme; it was really a proposal to simplify it. Natur-kunde-an elementary knowledge of nature-was to be admitted, but its admission was to be accompanied by a revision of our ambitious fourth schedule, and by the exclusion from it of mathematics, German, mechanics, animal physiology, physical geography, and botany... The excuse for putting most of these matters into our programme is that we are all coming to be agreed that an entire ignorance of the system of nature is as gross a defect in our children's education as not to know that there ever was such a person as Charles the First. Now our ordinary class-programme provides, or at any rate suggests, some remedy against the second kind of ignorance, for history is one of our class-subjects; ${ }^{32}$ it provides none against the first. This is a blot; we ought surely to provide that some knowledge of the system of nature should form part of the regular class course. Some fragments of such knowledge do in practice form part of the class course at present. Children in learning geography are taught something about the form and motion of the earth, about the causes of night and day and the seasons. But why are they taught nothing of the causes, for instance, of rain and dew, which are at least as easy to explain to them, and not less interesting? And this is what the teaching of Natur-kunde or natural philosophy (to use the formerly

${ }^{28}$ Huxley's "Science and Culture." Huxley's lecture, of course, was given four years later; and this proves that Arnold's thoughts on the subject clearly antedated this controversial incident; they had, in fact, been categorically stated twelve years earlier, in 1868 (cf. Higher Schools and Universities in Germany, London, 1892, pp. 162 ff.).

${ }^{29}$ Reports on Elementary Schools, p. 200.

${ }^{30}$ For 1876 , quoted supra.

${ }^{31}$ By 1867, the desiccating effects of the Revised Code in drawing all instructional attention to the grant-earning tools-reading, writing, and ciphering-had become apparent to the most uncritical observers. In that year, therefore, the Committee of Council issued a Minute instituting an additional grant, dependent, among other conditions, upon the inclusion of "one or more specific subjects of secular instruction."

${ }^{32}$ The Code of 1867 required the offering of only "one or more specific subjects of secular instruction" and did not prescribe what these should be. The inclusion, then, of any one subject would be purely elective.

(Continued on page 268) 